\title{
APRENDER/ENSINAR FILOSOFIA EM LÍNGUA GESTUAL PORTUGUESA
}

\author{
Fátima Sá Correia ${ }^{1}$ \\ Orquídea Coelho ${ }^{2}$
}

\begin{abstract}
Resumo
Admitindo que "la philosophie trouve son élément dans la langue dite naturelle" (DERRIDA, 1988, p. 36) e defendendo uma visão linguístico-cultural da surdez, as aulas de Filosofia em contexto de surdez colocam problemas específicos. A tradução de conceitos filosóficos para língua gestual apresenta dificuldades particulares devido às caraterísticas das duas línguas (língua vocal e língua gestual/língua de sinais). Além disso, nem todos os conceitos filosóficos possuem gesto standard em língua gestual portuguesa. Dado o compromisso teórico e o imperativo legal (legislação portuguesa) de as aulas de Filosofia ocorrerem em língua gestual portuguesa, procurou-se perceber de que modo esta língua resolve o problema da ausência de gesto. Nesse sentido, solicitou-se a um grupo de docentes surdas/os de língua gestual portuguesa que explicassem textos filosóficos nos quais estão presentes alguns desses conceitos e analisaram-se essas produções gestuais com o intuito de extrair resultados elucidativos.
\end{abstract}

Palavras-chave: Língua Gestual Portuguesa; Filosofia; Tradução

\footnotetext{
${ }^{1}$ Doutoranda em Ciências da Educação, Faculdade de Psicologia e de Ciências da Educação, Universidade do Porto (Porto/Portugal). Endereço: Rua Alfredo Allen, 4200-135 Porto, Portugal. Endereço Eletrônico: pdce10014@fpce.up.pt.

${ }^{2}$ CIIE - Centro de Investigação e Intervenção Educativas, Faculdade de Psicologia e de Ciências da Educação, Universidade do Porto (Porto/Portugal). Endereço: Rua Alfredo Allen, 4200-135 Porto, Portugal. Endereço Eletrônico: orquidea@fpce.up.pt.
} 


\section{INTRODUÇÃO}

Partimos de uma concepção linguístico-cultural da surdez e defendemos que a filosofia é feita na língua natural de quem a faz. A esta exigência teórico-cultural resultante da ligação constitutiva entre filosofia e língua natural, acrescenta-se, atualmente em Portugal, uma exigência legal. Com efeito, a legislação portuguesa relativa à educação de crianças e jovens surdas e surdos (Lei 21/2008) determina que, nas escolas de referência para a educação bilingue de alunos surdos (EREBAS), todas as aulas sejam lecionadas em Língua Gestual Portuguesa (LGP) e que, quando as/os docentes não forem fluentes em LGP, seja obrigatória a presença de um/a intérprete que assegure a tradução entre as duas línguas (Língua Portuguesa (LP) e LGP). Ora, esta exigência legal constitui, no caso da disciplina de Filosofia, um desafio particular dadas as especificidades quer da língua gestual (LG) quer da filosofia e levanta a questão de tentar perceber como é que a LGP constrói o discurso filosófico.

Vamos começar por fazer um enquadramento teórico-concetual da nossa investigação, ainda em curso, caraterizando a LGP, esclarecendo o nosso entendimento de filosofia e expondo as questões que a tradução levanta. De seguida, apresentamos o trabalho empírico realizado com gestuantes surdas/os sobre textos filosóficos.

\section{ENQUADRAMENTO TEÓRICO-CONCETUAL DO ESTUDO}

\subsection{A língua gestual portuguesa}

A Língua Gestual Portuguesa (LGP) é, "a língua usada pela maioria dos surdos profundos portugueses” (AMARAL, 1994, p. 25) e, a Constituição da República Portuguesa considera-a "expressão cultural e instrumento de acesso à educação e da igualdade de oportunidades" (artigo 74, 2., alínea h)). Trata-se de uma língua visuo-motora, cuja produção se processa através dos gestos e das expressões facial e corporal, e cuja percepção se realiza através da visão. De acordo com Amaral (1994) não existe uma comunicação universal entre as pessoas Surdas, tal como não existe entre as pessoas ouvintes, isto é, cada comunidade (Surda ou ouvinte) possui a sua língua. No entanto, devido à influência da metáfora e da 
iconicidade na sua estrutura, todas as LG partilham determinadas estruturas morfológicas (TAUB, 2004).

As LG possuem todas as caraterísticas de uma língua natural: a propriedade da criatividade, tanto no plano lexical como sintático, a propriedade de deslocamento, isto é, a possibilidade de as mensagens se referirem a objetos ou a acontecimentos afastados no tempo ou no espaço do lugar da gestuação, a dupla articulação os gestos - unidades significantes mínimas dividem-se em unidades mais pequenas não-significantes que se combinam para formar os signos de acordo com regras e constrangimentos sistemáticos, tal como as palavras se compõem de sons e esses sons se combinam segundo regras sistemáticas.

A LGP, tal como as outras línguas gestuais (LG) é, atualmente, reconhecida como uma língua verdadeira com estatuto igual ao das línguas vocais (LV). Assim, a LGP é um sistema linguístico, composto predominantemente por símbolos arbitrários e partilhada por uma comunidade de gestuantes nativos; tal como as LV, possui propriedades como recursividade, criatividade, contrastividade e está em constante evolução e renovação (Amaral, 1994). Desempenha também as mesmas funções que Jakobson definiu para as LV: referencial, emotiva, conotativa, fática, metalinguística e poética. Apesar destas semelhanças, no entanto, a LGP, tal como qualquer outra língua gestual (LG) apresenta especificidades relacionadas com a modalidade da sua produção das quais salientamos o uso do espaço, a simultaneidade, a quadrimensionalidade e a iconicidade.

Em primeiro lugar, destacamos o facto de nas LG, existir um uso linguístico, extremamente complexo, do espaço (tanto ao nível lexical como ao nível gramatical e sintático). Na produção do discurso, a/o gestuante evolui num espaço de gestuação determinado por um eixo central de comunicação entre o gestuante (emissor) e o recetor. Tudo o que, nas LV, ocorre linear, sequencial e temporalmente, nas LG ocorre simultaneamente, concorrentemente e em vários níveis (Quadros, 2004, Sacks, 2002). Além disso, a fala só tem uma dimensão (duração no tempo) enquanto as LG têm quatro dimensões (as três dimensões do espaço mais a dimensão tempo). De acordo com Vermeerberger (2006), o uso simultâneo das duas mãos como dois canais autónomos paralelos, em que cada um codifica gestos diferentes, permite a produção simultânea de diferentes elementos durante o discurso, dando às LG a possibilidade de refletir sobre o próprio conhecimento devido a esse uso simultâneo das duas mãos. 
Ora, a quadrimensionalidade do canal cria certas particularidades. Devido a esse suporte quadrimensional oferecido pelo canal visuo-gestual e pela capacidade cognitiva e linguística do sujeito Surdo em anamorfosear o real, as LG têm a possibilidade de construir o discurso a partir de dois domínios de representação: dizer e figurar. Essa capacidade de "mostrar", de "dizer dando a ver" dá às LG um lugar privilegiado na reflexão sobre a transmissão de conhecimentos (Cuxac, 2001). Segundo este autor, Cuxac (2001) existem de dois modos de dizer em LG, dizer sem mostrar - o léxico - e dizer dando a ver - estruturas de grande iconicidade. Estas estruturas de grande iconicidade (transferts) correspondem a uma modalidade do dizer (dizer mostrando) que não tem equivalente nas LV.

Quanto à iconicidade, podemos afirmar que as LG são produtoras de imagens no verdadeiro sentido do termo (imago, em latim, significa representação visual), na medida em que os signos são recebidos visualmente (BOUVET, 2011).

Apesar de durante muito tempo ser considerada não-linguística, a iconicidade é uma caraterística incontornável das LG está presente em todos os níveis da estrutura linguística (morfologia, sintaxe, léxico).

Cuxac (2001) defende mesmo que as LG devem ser apreendidas a partir da iconicidade, rejeitando, deste modo, a submissão das LG às LV. Segundo este autor, a iconicidade é o princípio estruturante das LG e é também o modo de produção do sentido. Como refere Garcia (2010), no discurso, existem imbricações constantes entre unidades lexicalizadas e unidades altamente icónicas e, nos próprios gestos standard (unidades leximáticas) existe também uma forte carga de iconicidade.

Precisemos o que queremos dizer ao afirmar que as LG são línguas icónicas. Quando falamos de iconicidade estamos a defender que a iconicidade não é apenas uma questão de semelhança entre forma e significado mas antes um processo complexo em que os "recursos fonéticos admissíveis de uma língua são construídos num «analógico» de uma imagem associada com o referente" ${ }^{, 3}$. Este processo envolve trabalho concetual que vai desde a selecção da imagem, mapeamento concetual e esquematização de itens "para se ajustarem às restrições da língua"4. Com efeito, a iconicidade deve-se a um esforço mental dos seres humanos e depende das nossas associações concetuais, mentais e culturais (TAUB, 2004, p. 20).

\footnotetext{
3 "allowable phonetic resources of a language are built u pinto na "analogue" of na image associated with the referente".

4 "to fit the constraints of the language".
} 
Taub (2004, p. 19-20) chama a atenção para o facto de a iconicidade não ser uma relação objetiva entre imagem e referente, mas sim uma relação entre os nossos modelos mentais de imagem e referente. Ora esses modelos mentais são, em parte, motivados pelas nossas experiências corporificadas (embodied experiences) comuns a todos os seres humanos e, em parte, motivados pelas nossas experiências em culturas e sociedades particulares, pelo que a definição de iconicidade tem de ter em conta a cultura e a concetualização (Taub, 2004, p. 19-20).

Assim, a iconicidade - iconicidade cognitiva - é uma relação não entre palavras e o mundo mas entre as nossas conceções mentais de uma forma de um item linguístico e o seu significado (Taub, 2004).

Relativamente à LGP, segundo Amaral (1994), a iconicidade (relação direta entre os gestos e aquilo que representam) pode estar presente mas não é dominante; existem gestos icónicos, gestos referenciais (que correspondem aos deíticos das LV e gestos arbitrários.

Para além destas especificidades das LG consideramos que se deve ter em conta também que a LG, como qualquer outra língua, é um fenómeno sociocultural e uma instituição social (Shaumyan, 2006) e que existe uma interdependência entre pensamento e linguagem. Assim, de acordo com Taub, "a língua está profundamente entrelaçada com as nossas experiências do mundo: a nossa interação social, as nossas instituições culturais, e até os nossos pensamentos são muitas vezes enquadrados e mediados através da língua"5 (TAUB, 2004, p. 10).

Neste mesmo sentido, e no que concerne as LG, Wilcox (2000) defende a ideia de que o estudo das metáforas em língua gestual não pode realizar-se sem se equacionar a influência da cultura. E, considerando que as comunidades surdas se caraterizam por uma apreensão de mundo essencialmente visual, defende que o motor cognitivo visual tem uma importância na organização de elementos da cultura e varia de acordo com a organização social.

De acordo com o relativismo linguístico (mesmo na sua versão moderada) a língua é um molde do pensamento e todas as línguas humanas envolvem uma perspetiva diferente do mundo (Chandler, 1994). De acordo com Delaporte (2002), para falar uma LG exige-se que a/o gestuante seja capaz de pensar com imagens. Assim, o domínio da LG não é apenas uma questão de habilidade linguística mas também uma questão cultural.

\footnotetext{
5 "Language is deeply interwoven with our experiences of the world: our social interaction, ours cultural institutions, even our thoughts, are often framed and mediated by language".
} 
Em resumo, como afirma Ladd (2003) existe um modo Surdo de pensar e de ver o mundo, isto é existe uma epistemologia Surda.

\title{
2.2 A filosofia
}

\begin{abstract}
Não se pode em geral chamar filósofo àquele que não consegue filosofar. Apenas se filosofa mediante o exercício e o uso da própria razão.

Mas como se aprenderá, então, a filosofia? Todo o pensador filosófico constrói, por assim dizer, a sua própria obra sobre as ruínas de outro, e jamais alguma obra se efectuou que permanecesse sólida em todas as suas partes. Já por isso se não pode, de raiz, aprender a filosofia, porque ainda não existe. (...) quem deseje aprender a filosofar deve encarar todos os sistemas de filosofia apenas como histórias do uso da razão e como objetos do exercício do seu talento filosófico.

(...) $\mathrm{O}$ verdadeiro filósofo deve, pois, como alguém que pensa por si, fazer um uso livre e autónomo da sua razão, e não de um modo servil e imitativo. (KANT, 2009, p. 30).
\end{abstract}

As autoras deste trabalho partilham esta conceção kantiana e é com ela que fazem a leitura do Programa de Filosofia em vigor para o Ensino Secundário que, como se verá, não parece afastar-se dela. Com efeito, de acordo com o Programa, o que se pretende é que, conhecendo conceitos e teorias que a História da Filosofia consagrou, as alunas e os alunos, mediante o uso da sua razão, construam um saber pessoal. Consideramos, também, que o exercício da razão se deve aplicar sobre o mundo envolvente: as alunas e os alunos devem desenvolver uma visão crítica da realidade que lhes permita serem plenamente humanas/os, no sentido de emancipadas/os do determinismo que regula a natureza.

A questão que se levanta é saber que língua deverá ser feito esse exercício da razão, em contexto de Surdez. O trabalho filosófico utiliza uma linguagem específica e trabalha com conceitos também eles específicos que possuem uma história, história essa que se confunde com a História da Filosofia, pelo que na disciplina de filosofia há um conteúdo conceptual a aprender/ensinar.

Ora, a língua é um sistema que permite representar o mundo, isto é, voltar a apresentá-lo, torná-lo, de novo, presente, é produto mas também produtora de cosmovisões. "Cada uma das línguas humanas traça do mundo um mapa diferente. (...) Cada língua - e sem que haja línguas 'pequenas' ou menores - constrói um conjunto de mundos possíveis e de geografias da memória" (STEINER, 2002, p. 18). Por isso, continua o autor "quando uma língua morre, é um mundo possível que morre com ela" (ibidem). 
Esse sistema, qualquer que ele seja, vai, por isso mesmo, condicionar a visão que o sujeito tem do mundo, pelo que a língua em que se faz filosofia parece ser um facto incontornável. Nesse sentido, o filosofar estará penetrado pela língua em que se filosofa.

Ora a língua natural das pessoas Surdas é a LG, conforme é reconhecido nos normativos legais (Constituição da República Portuguesa, art $^{\circ}$ 74, alínea h) e Lei 21/2008). Por isso, se, a língua natural é o espaço da filosofia (DERRIDA, 1988, p. 36), o filósofo tem de ter consciência das dificuldades impostas pelo uso das línguas naturais à comunicação. Nesta perspetiva, a filosofia será, então, uma área de conhecimento em que o/a autor/a e a língua da produção desse conhecimento são incontornáveis e os conceitos são criados e recriados pelo ato de filosofar na medida em que quando se filosofa se produz filosofia e a filosofia é o conteúdo que gera o filosofar (Aspis, 2004).

Além disso, as/os estudantes de Filosofia têm de conhecer conceitos e teorias mas não reproduzi-los apenas; devem aprender a questioná-los e a relacionar diferentes interpretações da realidade. Assim, uma educação filosófica que inclua o conhecimento da história da filosofia, do pensamento dos diferentes filósofos e respetivos argumentos, bem como do léxico filosófico poderá ser benéfica mas não é suficiente (Rudisill, 2011) e os benefícios dessa educação só se manifestam quando as/os estudantes forem capazes de filosofar: a aquisição de conhecimentos é apenas "uma parte do tornar-se filósofo"6 (RUDISILL, 2011, p. 241). É preciso, segundo este autor, começar por ler e interpretar textos filosóficos e isso é já estar a caminho de se tornar filósofo.

Centrando-nos no ensino da filosofia (na medida em que isso é possível) defendemos que ensinar filosofia e filosofar são inseparáveis ou, como afirma Aspis (2004): “O ensino de filosofia deve ser produção de filosofia, deve ser filosofar” (ASPIS, 2004, p. 308). Assim sendo, a filosofia tem um papel na formação das/os jovens estudantes, propiciando condições para que estas/es desenvolvam um pensamento autónomo, consciente, responsável e revisível, isto é, um "pensamento criativo, capaz de rir de si mesmo, buscador de compreensão, sempre atento ao seu tamanho justo" (ASPIS, 2004, p. 309). Ora, segundo esta autora, "o ensino da filosofia como experiência filosófica" levará, assim, ao desenvolvimento de um pensamento que não permite o preconceito e é fator de libertação "das opiniões, das obrigações, da preguiça e do medo" (ibidem).

\footnotetext{
6 "a part of becoming a philosopher".
} 
Assumindo esta perspetiva da filosofia como crítica, a UNESCO tem vindo a defender uma visão da filosofia como «une école de la liberté» (Stratégie Intersectorielle de l'UNESCO Concernant la Philosophie, 2005), considerando-a um verdadeiro exercício da liberdade que desempenha um papel crucial no desenvolvimento do pensamento livre e na reflexão sobre a realidade envolvente (UNESCO. Stratégie Intersectorielle Concernant la Philosophie, 2006).

Concordamos que as aulas de filosofia, como lugar da experiência filosófica, têm como objetivo oferecer critérios filosóficos para o aluno julgar a realidade por meio da prática do questionamento filosófico e da construção de conceitos, por meio do exercício da criatividade e avaliação filosóficas e, por isso aceitamos que "Para nós as aulas de filosofia são aulas de filosofar da mesma forma que ensinar filosofia é produzir filosofia. Assim sendo, aulas de filosofia são produção de filosofia” (ASPIS, 2004: 310).

Ora, neste processo de ensino/aprendizagem da filosofia é necessário ter em conta as referências das alunas e dos alunos, na medida em que "o seu pensamento não é uma 'tábua rasa' sobre a qual se possam depositar os conteúdos da tradição filosófica, nem um amontoado de pensamentos dominados pelos preconceitos e erros do conhecimento vulgar" (FERRIOL, 2005: 610) na medida em que as mentes das alunas e dos alunos possuem já (pelos menos potencialmente) a criatividade e a criticidade que, como dissemos, são características do pensamento filosófico (FERRIOL, 2005).

Esta é, em nosso entender, a perspetiva defendida pelo programa de Filosofia para o ensino secundário segundo o qual a disciplina de Filosofia deverá contribuir para o desenvolvimento intelectual (desenvolvimento do raciocínio, da reflexão e da curiosidade científica, compreensão do carácter limitado e provisório dos nossos saberes), social (desenvolvimento de um pensamento ético-político crítico e responsável e do espírito democrático), cultural (desenvolvimento de uma sensibilidade cultural e estética, aberta à diversidade cultural) e pessoal (construção de um projecto de vida próprio, da identidade) de cada jovem que, no mundo actual, precisa de dar a conhecer as suas convicções e de saber avaliar as dos outros (Programa de Filosofia para o $10^{\circ}$ e $11^{\circ}$ anos).

Assim, assumindo que a língua molda o pensamento e que a filosofia também é moldada pela língua, que a filosofia tem um papel de desenvolvimento do espírito crítico e que o ensino da filosofia no ensino secundário tem como objetivos o desenvolvimento da/o jovem, defendemos que aprender/ensinar filosofia em LG é uma questão cultural, é uma 
questão de bilinguismo/biculturalismo que não se compadece com uma simples tradução do discurso da/o docente pensado e dito em LP.

O trabalho na aula de Filosofia em contexto de surdez deverá, portanto, em nosso entender, consistir numa explicação do(s) conceito(s) filosófico(s) em LGP por meio de gestos standard e transferts (Cuxac, 2001) ou metáforas (Taub, 2004; Wilcox, 2000), reutilização de gestos standard preexistentes - por composição e empréstimo interno (Mineiro, 2009), ultrapassando o problema da não existência de gestos standard para alguns conceitos filosóficos.

\subsection{A tradução}

No caso da filosofia, a tradução coloca questões incontornáveis. Com efeito defendemos que a tese da traduzibilidade é insustentável na medida em que a língua não é mera nomenclatura e que uma das especificidades dos conceitos filosóficos consiste no facto de serem inseparáveis da história da filosofia e imbuídos da língua da sua produção e, por isso mesmo, não poderem ser ditos noutra língua. Nessa medida, alguns conceitos filosóficos perdem sentido quando traduzidos, pelo que toda a tradução está condenada a falhar.

\footnotetext{
Minha senhora, o seu tradutor é um tradutor muito bom, um tradutor credenciado, um tradutor excelente, mas traduz as palavras e não o sentido; para dizer 'acidente', ele pega na palavra que se utiliza para o 'acidente' de carro. A ambiguidade, nem sequer a imagino, mas pergunto-me o que é que as pessoas conseguiram compreender. ${ }^{7}$ (CASSIN, 2006).
}

Se é difícil/impossível traduzir filosofia de uma língua para outra, tratando-se de LV línguas da mesma modalidade -, mais difícil/impossível ainda é traduzir entre línguas de modalidades diferentes, dadas as características das duas línguas em presença que atrás apresentamos.

A tradução de e para uma língua gestual apresenta-se como uma caso específico de tradução na medida em que as duas línguas em presença são línguas de modalidade diferente pois não utilizam o mesmo canal: uma é oro-fonadora e a outra visuo-gestual. Além disso, a

\footnotetext{
7 "Madame, votre traducteur est un très bon traducteur, c'est un traducteur assermenté, un excellent traducteur. Mais qui traduit les mots et pas le sens; pour dire 'accident', il prend le mot qu'on utilise pour l"accident' de voiture. L'équivoque, je ne l'avais même pas imaginée, mais je me demande ce que les gens ont pu comprendre».
} 
linearidade e a sequencialidade são características das LV, enquanto a quadrimensionalidade e a simultaneidade caracterizam as LG.

Ora a utilização do tempo e do espaço permite uma simultaneidade de informações o que faz com que o gesto forneça duas vezes mais informações, apesar de demorar mais tempo a formar-se do que uma palavra (Jeggli, 2003).

Um dos aspetos notáveis de todas as LG reside no facto de, na falta de gestos (signes) lexicalizados aquando da expressão de conteúdos informacionais difíceis de transmitir, as/os gestuantes surdas/os podem sempre recorrer à estratégia produtiva de «dar a ver», reativando o processo de iconicização como outro ramo a explorar; esta passagem para a visée illustrative com o objetivo de construir um conceito novo que não tem gesto (signe) lexicalizado estabelece uma forte correlação entre os ramos de visées no que concerne os processos de criação de gestos (signes) com valor generalizante (Fusellier-Souza, 2006).

Também Cassin (2006) admite a dificuldade de traduzir em filosofia e considera que essa dificuldade constituiu o ponto de partida da criação do Vocabulaire européen des philosophies; dictionnaire des intraduisibles. No entanto, segundo a autora, o termo 'intraduzíveis' que consta do título da obra não significa que esses termos não possam ser traduzidos mas apenas que a sua tradução constitui um problema cuja solução pode implicar a criação de um neologismo ou de um sentido novo para um termo já existente.

Com efeito, nem os termos nem as redes conceituais são sobreponíveis em línguas diferentes. A título de exemplo, na apresentação do Vocabulaire européen des Philosophies, Cassin (2004) questiona-se se sobre o rigor da tradução do alemão 'Geist' para o inglês 'mind' ou para o francês 'esprit', bem como do russo 'pravda', para o francês 'justice' ou 'vérité'.

Além destas dificuldades acresce o facto de alguns conceitos filosóficos não terem um gesto standard correspondente em LGP, ou o gesto existente remeter para um significado diferente.

No entanto, segundo Jeggli (2003), a falta de léxico standard não é tanto problema para as Surdas e os Surdos como para as/os intérpretes e docentes que ensinam directamente em LG. Com efeito, as Surdas e os Surdos não se poupam nas perífrases e, além disso, a grande iconicidade que caracteriza as LG permite dizer muitos conceitos sem recorrer ao léxico standard (Jeggli, 2003). 
CORREIA, F. S.; COELHO, O.

\section{TRABALHO EMPÍRICO}

\subsection{Objetivos da investigação}

O principal objetivo desta investigação foi compreender de que modo a Língua Gestual Portuguesa (LGP) consegue construir um discurso filosófico na ausência de gestos correspondentes a alguns conceitos filosóficos. Este objetivo decorre quer de um imperativo legal, quer das conceções teóricas por nós defendidas. Com efeito, a exigência de as aulas de Filosofia serem lecionadas em LGP resulta de uma prescrição legal (Lei 21 de 2008) e também da nossa assunção de posições acerca da comunidade Surda (minoria linguísticocultural), da especificidade da língua gestual (nomeadamente a iconicidade) e da filosofia (como atividade de pensar mas também como área do conhecimento em que conceitos e teorias estão penetrados pela língua em que se filosofa o que implica problemas específicos relativamente à sua tradução).

Não se pretende, porém, produzir um conhecimento prescritivo mas antes um conhecimento reflexivo. Dizemos que não pretendemos construir um conhecimento prescritivo no sentido em que não pretendemos generalizar para todas as LG, nem pretendemos criar um manual para as/os docentes de Filosofia nem tampouco um glossário de termos filosóficos em LGP. Pretendemos ver como se comporta a LGP perante o problema linguístico-cognitivo da ausência de léxico filosófico.

\subsection{Recolha de informação}

\subsubsection{Protocolo}

Para a recolha de informação adotamos o protocolo que descrevemos a seguir.

Começamos por estabelecer contacto com as/os eventuais colaboradoras/es, apresentando-lhes o projeto que pretendíamos realizar. Esclarecemos que, pretendíamos ver de que modo a LGP resolve o problema linguístico-cognitivo da ausência de gesto para dizer alguns conceitos filosóficos. Referimos os conceitos de 'raciocínio' e 'racionalismo' que não 
possuem entrada nem no Dicionário de Língua Gestual Portuguesa (Baltazar, 2010) nem no Gestuário (Ferreira, 1995) e os conceitos de 'razão' e 'racional' (que não possuem entrada no Gestuário) e cujos gestos existentes (de acordo com o Dicionário) remetem para sentidos diferentes dos que são veiculados pelos conceitos de 'razão' e 'racional' tal como estão presentes nos extratos apresentados.

Uma vez aceite a nossa proposta, apresentamos-lhes os textos que pretendíamos filmar para que pudessem ter um primeiro contacto com eles e fazerem um levantamento de eventuais dúvidas para posterior esclarecimento. Foi também esclarecido que o que pretendíamos não era que fizessem uma tradução dos textos propostos mas que os dissessem em LGP, isto é, que transmitissem em LGP o sentido do texto.

De acordo com a disponibilidades das/os colaboradoras/es, foram marcadas datas para se proceder às gravações. Quando, na data marcada, compareceram na sala do Projeto Spread the $\operatorname{Sign}^{8}$, as/os colaboradoras/es foram esclarecidas/os acerca de eventuais dúvidas que entretanto tivessem surgido e foi-lhes dado o tempo que consideraram necessário para se prepararem. As gravações foram feitas na sala do referido projeto, na Faculdade de Psicologia e de Ciências da Educação da Universidade do Porto, por colaboradores surdos e ouvintes desse projeto.

Deste modo foi constituído um corpus de 32 gravações vídeo das produções em LGP feitas pelas/os gestuantes surdas/surdos a partir de quatro extratos de textos. Cada um destes textos inclui um dos conceitos filosóficos em questão.

Uma vez constituído o corpus, fizemos uma leitura das diferentes gravações, por texto e por gestuante de acordo com a seguinte grelha:

\footnotetext{
${ }^{8}$ O Spread The Sign (STS) é um dicionário online de línguas gestuais e línguas vocais, multilingue e de acesso livre/gratuito (www.spreadthesign.com), que se encontra na $3^{\mathrm{a}}$ edição financiada pelo Fundo Social Europeu ( $1^{\mathrm{a}}$ Edição - Spread the Sign, (SE/06/B/F/LA-161015, d-nr 4738-2005); $2^{\mathrm{a}}$ Edição - Spread the Sign, Communication

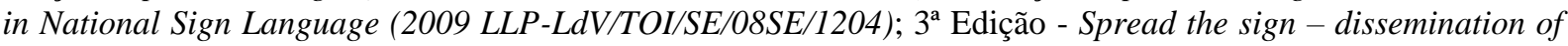
vocational sign language in Europe, 526361-LLP-1-2012-1-SE-LEONARD-O-LNW).
} 
CORREIA, F. S.; COELHO, O.

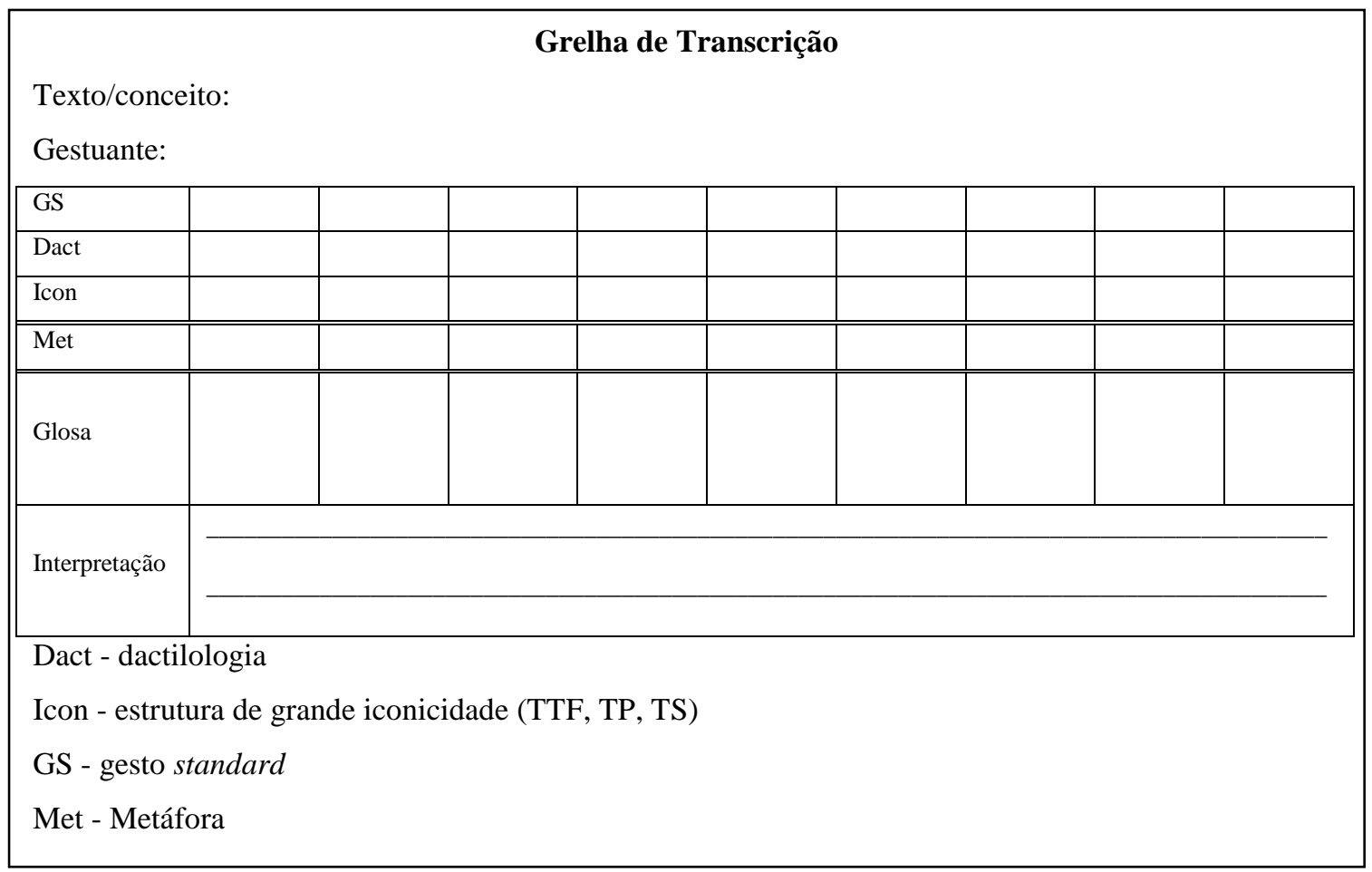

\subsubsection{Critérios de escolha dos conceitos, dos textos e das/os colaboradoras/es Critérios de escolha dos conceitos}

Uma vez que tínhamos como horizonte de referência o Programa de Filosofia para o ensino secundário, atualmente em vigor em Portugal, escolhemos conceitos que consideramos relevantes em função desse programa tendo o conceito de 'razão' surgido como o conceito que lhe subjaz. Com efeito, este programa assenta na distinção entre racionalidade filosófica, argumentativa e científica. A este conceito apareceram ligados os conceitos de 'racional', 'racionalismo' como teoria explicativa do conhecimento e 'raciocínio', requisito prévio a toda a unidade de Lógica

Atendemos também ao facto da não-existência de gesto correspondente em LGP e/ou ao facto de o gesto standard existente ter um sentido diferente daquele que a tradição filosófica consagrou, como acima referimos.

Relativamente à inexistência de gesto standard encontramos os conceitos de 'raciocínio' e 'racionalismo', de acordo com o Dicionário de LGP (2010) e com o Gestuário (1995), como também já referimos.

Quanto à segunda hipótese, constatamos que para a entrada 'razão' é apresentado o gesto que em LGP significa 'estar certo' 'estar na posse da verdade' e se aproxima do gesto de 
verdade. O mesmo acontece com 'racional' como sendo 'ligado a 'razão'. Com efeito, o gesto de 'razão' “(...) mão dominante em configuração 'u' inicia junto da boca e realiza movimento descendente, tocando duas vezes na palma da mão não dominante em configuração '1'” (Baltazar, 2010, p. 923), aproxima-se do gesto de 'verdade' "mão dominante em configuração ' $u$ ' inicia junto da boca e realiza movimento descendente incisivo, terminando na palma da mão não dominante em configuração '1'”' (BALTAZAR, 2010, p. 917).

Por sua vez, o gesto para 'racional' é formado pelo "gesto 'ligado' seguido do gesto 'verdade"” (BALTAZAR, 2010, p. 917) vem reforçar o sentido de 'razão' igual a 'verdade', «ter razão», «estar certo», mas não remete para a ligação com "faculdade de raciocinar discursivamente, de combinar conceitos e proposições” (LALANDE, 1985, p. 372).

Consultado o Gestuário (1995), constatamos que não existe entrada nem para 'razão', nem para 'racional'.

Ora, o Programa de Filosofia convoca o conceito de 'razão' como faculdade, ligando-o a um conjunto de outros conceitos, indispensáveis à filosofia e ao filosofar, entre os quais selecionámos 'racionalidade', 'racionalismo' e 'racional'.

Perante esta situação pretendemos ver de que modo a LGP resolve esse problema linguístico-cognitivo da ausência de léxico standard (ou existência de gesto standard com outro sentido).

\subsubsection{Critérios de escolha dos textos}

A escolha de textos teve em atenção, o facto de o conceito a trabalhar ser o único presente no texto que não tivesse gesto correspondente em LGP e que esse conceito fosse claro e distinto, isto é que fosse facilmente compreensível e não dependesse de ou condicionasse outro(s) conceitos filosóficos para ser compreendido.

Escolhemos textos de dois filósofos consagrados na História da Filosofia, aquilo a que o Programa designa de "textos que o canon catalogou de filosóficos (Programa de Filosofia $10^{\circ}$ e $11^{\circ}$ anos - Cursos Gerais e cursos Tecnológicos. Formação Geral, 2001, p. 17) mas também outro tipo de textos, como também é proposto pelo referido Programa. Assim, além de dois extractos de Platão (Teeteto, 200d-202d) e de Descartes (Discurso do Método, p. 97), selecionamos um extrato de Maurice Gex (Logique Formelle, p. 11-12, para o conceito de 
'raciocínio' e um de Hessen (Teoria do Conhecimento, 1973, p. 60-61), para o conceito de 'racionalismo'.

Do ponto de vista formal, atendemos à clareza da construção gramatical e à dimensão reduzida do texto. Este último requisito decorreu do tipo de tarefa que se exigia às/aos gestuantes: dizer o sentido de um texto sem o ter presente, o que envolve a necessidade de memorização do mesmo. Embora as/os gestuantes pudessem consultar o texto, se assim o entendessem, precisavam de ter memorizado a ideia central do mesmo pelo que não se podia trabalhar com textos muito longos.

\subsubsection{Critérios de escolha das/os colaboradoras/es}

Seguindo Bourdieu (2007), tentamos reduzir a violência simbólica que se exerce em qualquer relação social, embora tenhamos consciência da impossibilidade da sua eliminação, procurando controlar o nível da linguagem utilizada e a escolha das/os colaboradoras/es. No que concerne essa escolha, Bourdieu (2007) defende que as/os investigadoras/es têm a liberdade de escolher as/os suas/seus colaboradoras/es entre pessoas conhecidas ou a quem estas as/os pudessem apresentar, defendendo que uma comunicação «não violenta» assenta na familiaridade e na proximidade social. Tudo isto nos levou a escolher pessoas Surdas já nossas conhecidas, ou que nos foram apresentadas por estas últimas. Este conhecimento prévio das investigadoras e das/os colaboradoras/es contribuirá, em nosso entender, para que se estabeleça um clima de confiança mútua.

Foi também critério de escolha o reconhecimento das/dos colaboradoras/es pela comunidade Surda enquanto possuidores de uma forte identidade Surda.

A necessidade de perceber a viabilidade de a LGP construir um discurso filosófico obrigou-nos a atender ao domínio da LGP por parte das/dos colaboradoras/es e à existência de conhecimentos (ainda que básicos) de Filosofia. Assim, escolhemos docentes de LGP (com a licenciatura em Leccionação de Língua Gestual Portuguesa ou o Curso de formadores de LGP reconhecido pela Associação de Surdos do Porto) e que, cumulativamente, tenham tido a disciplina de Filosofia no ensino secundário. Com efeito, na ausência de instrumentos que nos permitissem avaliar a proficiência linguística de cada um/a, presumiu-se que o facto de serem docentes de LGP garantiria, pelo menos teoricamente, a qualidade da sua expressão em LGP. Desses docentes, escolheram-se aquelas/es que tiveram contacto com a disciplina de Filosofia 
(pelo menos ao nível do ensino secundário). A conjugação destes dois fatores deu-nos também, pelo menos em teoria, uma certa garantia da compreensão do texto filosófico escrito.

Temos consciência que para que possa emergir uma língua gestual "natural" (em vez de um artefacto de língua, composto apenas por signos do léxico) com muitas ocorrências de estruturas de grande iconicidade é importante que os gestuantes tenham nascido Surdos e pertençam à comunidade Surda, pois a consciência do contexto da cultura Surda levará à produção de uma LG muito imagística e distante das estruturas da língua escrita e falada dominante (SALLANDRE; CUXAC, 2002: 176 nota). Além disso, e segundo os mesmos autores, é importante que os/as gestuantes tenham confiança no/a investigador/a para serem capazes de produzir signos naturalmente. No caso desta tese não se tratou de nos colocarmos no pensamento do outro mas apenas de garantir a sua confiança para nos dar um texto «sem medo» (BOURDIEU, 2007).

Não foi feita nenhuma pesquisa para detetar o grau de perda auditiva na medida em que, de acordo com Sallandre (2003), nenhuma pesquisa em psicolinguística provou a existência de uma ligação entre a competência linguística e o grau de perda auditiva.

\subsection{Análise dos resultados}

\subsubsection{Dificuldades da transcrição de uma LG}

Segundo Boutora (2002), a descrição linguística de uma LG exige uma transcrição o mais fiel possível do corpus analisado. Ora, transcrever (apreender graficamente as formas faladas das línguas) é, forçosamente e por natureza, sempre um problema na medida em que o linguista é sempre (re)-leitor das suas próprias transcrições uma vez que existe sempre mudança de modalidade (e de dispositivo de receção/produção) (GARCIA, 2010: 47). A questão não se coloca, porém, da mesma maneira para as LG e para as LV, apesar das dificuldades existentes em ambas as situações. Com efeito, no caso de uma transcrição de LG para LV estamos perante duas línguas de modalidades diferentes que não utilizam o mesmo canal: a LG é uma língua visuo-gestual, enquanto a LV é oro-fonadora. Estas diferenças na recepção e produção conferem caraterísticas diferentes à LG (quadrimensionalidade e simultaneidade) e à LV (linearidade e simultaneidade). Como também foi referido no 
Enquadramento Teórico Concetual (ponto 1.1.), o uso das duas mãos, que funcionam como dois canais autónomos e paralelos, permite a produção simultânea de diferentes elementos durante o discurso. Esta situação, específica da LG, não tem equivalente nas LV o que torna a transcrição um problema incontornável.

Além disso, a análise da grande iconicidade (característica constitutiva das LG) é difícil de manipular e, de acordo com Cuxac (2001), a tradução de uma LG para uma LV faz perder/não diz nada sobre aspetos essenciais do discurso em LG, na medida em que nas LV não existe equivalente à opção linguística de "dizer dando a ver". Assim, consideramos que a transcrição envolve sempre interpretação.

Além disso, e de acordo com Garcia (2010), nenhuma escrita é o reflexo das regularidades de uma língua (apesar de captar qualquer coisa dessas regularidades) porque as interpreta em função das limitações e potenciais da sua modalidade própria, o mesmo se passando, por consequência, com a transcrição. As LG colocam, assim, problemas específicos em relação à escrita. Garcia (2010) defende que esses problemas têm menos a ver com as características modais e estruturais das LG mas antes com o facto de elas não disporem de um sistema próprio de transcrição. Por isso, escrita e transcrição têm de ser pensadas ao mesmo tempo e sem que nos possamos apoiar em "pré-saberes práticos e práxicos".

O facto de as LG não terem sistemas de escrita difundidos tem grandes implicações: para etiquetar e identificar os gestos por isso muitas/os investigadoras/es usam glosas (palavras da LV que se sobrepõem semanticamente (em larga medida, embora não totalmente) ao gesto que se pretende identificar e que dependem do conhecimento que o/a investigador/a tem da língua-alvo. Este procedimento embora seja cómodo apresenta fraquezas. Com efeito, o uso das glosas pode induzir em erro uma vez que sugere que a semântica da palavra ou frase da LV escolhida para a glosa coincide com a semântica do gesto (a total coincidência pode acontecer em alguns casos mas não em todos). O que acontece é que a maior parte dos gestos têm múltiplas possibilidades de tradução numa LV mas só uma variante pode ser escolhida na glosa.

Assim, e porque podemos dispor de uma forma de validação das nossas transcrições, tentando assegurar, de algum modo, a boa tradução das glosas e a coerência do conjunto, os/as colaboradores/as participaram no trabalho de revisão da nossa transcrição dos seus respetivos textos em LGP. Além disso, essa colaboração com pessoas Surdas deu origem a 
várias discussões em que se confrontaram as nossas interpretações de unidades ou de sequências ambíguas.

\subsubsection{Descrição de uma produção em LGP}

Cada produção em LGP foi transcrita para uma grelha (p. 13) onde ficou identificada/o a/o gestuante bem como o conceito/texto a que se refere essa produção. Ficaram registados os recursos utilizados seguindo-se a ordem temporal do seu aparecimento. Seguidamente, foi feita a glosa e a interpretação (em LP) da produção em LGP.

Apresentamos, a seguir, como exemplo, a análise de uma sequência em LGP referente ao texto sobre o conceito de 'razão'.

Texto em LP:

[...] os homens nascidos surdos e mudos estão privados, tanto ou mais do que os animais, dos órgãos que servem aos outros para falar e costumam inventar eles mesmos certos sinais, pelos quais se fazem entender por aqueles que, vivendo habitualmente com eles, têm ocasião de aprender a sua linguagem. E isso não prova apenas terem os animais menos razão do que os homens, mas não a terem de todo, pois vê-se que basta um tudo-nada de razão para saber falar (DESCARTES; p. 97).

Produção em LGP:

A gestuante efetuou os gestos standard [PESSOAS], [NASCER], [SURDASMUDAS] seguidos de uma pointage [essas] [FORMA] mão direita (aponta para o sítio onde tinha colocado as pessoas surdas-mudas) [FORMA] mão esquerda [ANIMAL] [EXATAMENTE IGUAL] [FALAR] [NÃO CONSEGUIR] [VEJAMOS] [SURDA] [PESSOA] [SURDA-MUDA] [ENCONTRAR] [PESSOAS] [IGUAL] (três vezes encontrar) [EU] $[\mathrm{SURDA}][\mathrm{ELE}] \quad[\mathrm{SURDO}][\mathrm{EU}]$ [ENCONTRO] (três vezes) [TENTAR] [COMUNICAR] [CRIAR (duas vezes] [RELACIONAR] (três vezes) [SIGNIFICA] [ANIMAIS] [ELES] [PENSAMENTO] [DELES] [NÃO HÁ] [COMUNICAR] [DENTRO] [NÃO HÁ] [PESSOA] [SURDA-MUDA] [ENCONTRAR] [COMUNICAR (duas vezes)] [ENTÃO] [PENSAMENTO] [TEM]

Interpretação: As pessoas que nascem surdas-mudas não conseguem falar exatamente como os animais. Vejamos, uma pessoa surda-muda encontra pessoas iguais, eu sou surda, encontro um surdo tento comunicar, criar, relacionar: quer dizer os animais não têm pensamento não. A pessoa surda-muda encontra [maneira de] comunicar logo tem pensamento. 
CORREIA, F. S.; COELHO, O.

A gestuante usou os gestos standard ([PENSAMENTO] e [PENSAR]) para resolver o problema da ausência de um gesto standard para 'razão'.

Relativamente a este conceito, constatámos que as/os outras/os gestuantes cujas produções já foram analisadas se socorreram também de gestos standard e de dactilologia.

Do mesmo modo foram analisadas todas as sequências, por gestuante, relativas aos outros conceitos ('raciocínio', 'racional' e 'racionalismo').

\subsubsection{Síntese da análise das produções LGP}

\subsubsection{Dactilologia}

Constatámos que a dactilologia foi utilizada como uma espécie de apresentação/título do texto em LGP e também como forma de dizer o conceito na ausência de gesto standard.

O recurso à dactilologia para apresentar o texto gestuado foi utilizado por seis dos oito gestuantes. Este uso ocorreu seguido de 'é igual':

[R-A-C-I-O-N-A-L] [É IGUAL] [POR EXEMPLO]; [R-A-Z-Ã-O] [O QUE É] [POR EXEMPLO].

Desses seis gestuantes, uma gestuante utilizou a dactilologia não só como apresentação/título mas também para dizer conceitos em três textos: no texto sobre 'razão', [R-A-Z-A-O- ] aparece no corpo do texto como substituto do gesto standard [RAZÃO], que remete para um significado diferente, sem que a gestuante tenha tentado dizer o conceito de outra forma (a gestuante tem consciência de que o gesto standard não corresponde ao sentido do texto mas não procura dizer esse conceito de outra maneira).

Também no texto sobre 'racionalismo', a gestuante, na ausência de gesto standard, recorre à dactilologia para dizer (R-A-Z-A-O- ) e (R-A-C-I-O-N-A-L-I-S-M-O).

\subsubsection{Gestos standard}

Constatamos que as/os gestuantes recorrem preferentemente a gestos standard existentes. Assim, o conceito de 'razão' (no sentido de faculdade humana de pensar) é dito 
mediante o recurso aos gestos standard [PENSAR], [PENSAMENTO], [CAPACIDADE + PENSAR], [PENSAR + TER].

Para dizer o conceito de 'raciocínio', as/os gestuantes usam os seguintes gestos standard: [PENSAR + LÓGICA], [PENSAR + DAR CONCLUSÕES], [CONCLUSÃO + HIPÓTESES VÁRIAS + ESCOLHER UMA], [PENSAR + PROBLEMA+ HIPÓTESE].

Para o conceito de 'racional' foram utilizados os gestos standard [PENSÉE + DAR + RAZÃO (VERITÉ)], [OPINIÃO + LIGAR + LÓGICA].

\subsection{Discussão da informação}

Após análise do corpus, constatamos que as/os gestuantes utilizaram os gestos standard para dizer os conceitos que pretendíamos trabalhar. Para isso, utilizaram dois procedimentos. Alguns/as gestuantes escolheram o gesto que melhor exprimia o sentido desse conceito no texto. Foi o que ocorreu quando usaram o gesto [PENSAR] ou [PENSAMENTO] para dizerem 'razão'. Outra opção foi a composição, isto é a expressão do conceito por meio da junção de gestos standard existentes sem perda de morfemas (gesto + gesto e gesto + gesto + ...) (MINEIRO, 2009, p. 90) como, por exemplo, quando para dizer raciocínio, o gestuante diz [CONCLUSÃO + HIPÓTESES + VÁRIAS + ESCOLHER + UMA).

Por sua vez, a dactilologia foi utilizada em duas situações: ou para fazer uma espécie de introdução/título ao que ia ser dito ou mesmo para dizer o conceito. O uso da dactilologia como apresentação do texto foi um recurso utilizado por seis das/os oito gestuantes,

A dactilologia com a função de dizer o conceito para o qual não existia gesto standard foi utilizada apenas por uma gestuante.

Ao utilizar a dactilologia um dos gestuantes cometeu um erro de ortografia ao escrever um conceito. Segundo Mineiro (2009), a utilização do alfabeto manual exige o conhecimento da LP escrita pelo que se poderá pensar no seu não domínio por parte deste gestuante mas isso embora esteja fora do âmbito desta investigação, poderá alertar-nos para as limitações do procedimento adotado nesta investigação.

Uma outra gestuante também cometeu um erro mas ela própria se autocorrigiu.

O não recurso à grande iconicidade como forma de dizer os conceitos veio contrariar as nossas expectativas. Uma vez que, de acordo com Cuxac (2001), as estruturas de grande iconicidade (tranferts) permitem dar a informação nova ainda não partilhada, esperávamos 
CORREIA, F. S.; COELHO, O.

que as/os gestuantes recorressem a essas estruturas para dizer os conceitos para os quais não existe gesto standard. Embora aceitemos que mesmo os gestos standard são icónicos pertencem, contudo, ao 'dizer sem dar a ver' e não ao 'dizer dando a ver' da grande iconicidade (CUXAC, 2001). Ora, o que constatamos foi que o recurso à grande iconicidade ocorreu em outros momentos do texto, nomeadamente no texto sobre 'raciocínio' para dizer “possibilidade de levar a água ao sítio por camião” e não para dizer 'raciocínio'.

\section{CONSIDERAÇÕES SOBRE O PROCEDIMENTO ADOTADO}

Ao realizar a análise do corpus constatámos que alguns/mas gestuantes não exprimiram o sentido do conceito, tendo-se centrado apenas nos exemplos e que o problema cognitivo-linguístico foi resolvido mediante o recurso a gestos standard existentes mediante processos de empréstimo interno e composição.

Esta constatação levou-nos a questionar em que medida a apresentação de um texto em LV (LP) escrita terá constituído um condicionamento à produção de uma LG autêntica na medida em que, de acordo com Perniss (2015), o uso das formas linguísticas de uma LV pode influenciar a estrutura da LG. A constatação destas limitações confrontou-nos com a necessidade de completar esta investigação com um trabalho sobre a LGP sem recurso à LP. Este novo passo terá o seguinte protocolo:

Escolha de três produções em LGP retiradas do corpus vídeo (escolha feita em colaboração com uma das colaboradoras Surdas). Seguidamente, apresentação dessas três produções a três gestuantes e promoção de uma discussão gravada em vídeo sobre os conceitos e respetivas interpretações com base na visualização dos vídeos. Realização de uma análise posterior da discussão no sentido de tentar perceber se e como as/os três gestuantes explicam/clarificam os conceitos.

\section{LEARNING/TEACHING PHILOSOPHY IN PORTUGUESE SIGN LANGUAGE}

\section{Abstract}


Assuming that "philosophy finds its place in natural language" (DERRIDA, 1988, p. 36) and a linguistic-cultural view of deafness, the Philosophy classes with deaf students pose specific problems. The translation of philosophical concepts raises particular difficulties due to the characteristics of the two languages (vocal language and sign language). In addition, not all philosophical concepts have standard gesture in Portuguese sign language. Given the theoretical commitment and the legal enforcement (Portuguese law) of all the classes being in Portuguese sign language we tried to understand how does this language solve the problem of the absence of standard sign. In order to do so we asked a group of deaf teachers of Portuguese sign language to explain philosophical texts in which exist some of those concepts. Subsequently, we analised those productions in order to find enlightening results.

Keywords: Portuguese Sign Language; Philosophy; Translation

APRENDER / ENSEÑAR FILOSOFÍA EN EL LENGUAJE GESTUAL PORTUGUESA

\section{Resumen}

Aceptando la perspectiva de que "la philosophie trouve son élément dans la langue dite naturelle" (DERRIDA, 1988, p 36), y una visión lingüístico-cultural de la sordera, el proceso de aprendizaje/enseñanza de la Filosofía, en alumnos sordos, coloca problemas específicos. La traducción de conceptos filosóficos en lengua de señas presenta dificultades particulares debido a las características de las dos lenguas en cuestión (lengua vocal - lengua de señas). Además de eso, no todos los conceptos filosóficos poseen una seña standard en lengua de señas portuguesa. Dada la obligatoriedad teórica y legal (de acuerdo con la legislación actual) de que las aulas de Filosofía sean en lengua de señas portuguesa, se intentó entender de qué modo la lengua de señas portuguesa resuelve el probema de la ausencia de seña. Se pidió a un grupo de docentes sordas/os de lengua de señas portuguesa que explicasen textos filosóficos en los cuales estuviesen presentes algunos de esos conceptos y se analizaron esas producciones gestuales.

Palabras-clave: Lengua Portuguesa de Señas; Filosofía; Traducción 


\section{REFERÊNCIAS:}

ALMEIDA, Maria M. B. (Coord.). Programa de Filosofia $10^{\circ}$ e $11^{\circ}$ anos: Cursos gerais e cursos tecnológicos: Formação geral. Lisboa: Ministério da Educação, 2001.

BALTAZAR, Ana Bela. Dicionário de língua gestual portuguesa. Porto: Porto Editora, 2010.

BOURDIEU, Pierre et al. Compreender. In: BOURDIEU, P.et al (Orgs.). A Miséria do mundo. $6^{\mathrm{a}}$ edição. Petrópolis: Editora Vozes , 2007.

BOUTORA, Leïla. Les stratégies d'interprétation réfléchie en langue des signes française. 2002. 65f, Mémoire (Maîtrise des Sciences du Language) - Université Paris VIII, Paris.

BOUVET, Danielle. Le Corps et la métaphore dans les langues gestuelles: à la recherche des modes de production des signes. Paris: Harmattan, 2011.

CASSIN, Barbara. Le vocabulaire européen des philosophes, dictionnaire des Intraduisibles: Entretien avec Barbara Cassin, philosophe et philologue, 2006. http://www.revuetexto.net/Dialogues/Cassin_interview.html.

CASSIN, Barbara. Le Vocabulaire européen des philosophes, dictionnaire des intraduisibles. Paris: Le Seuil. 2004.

CUXAC, Christian. Présentation. Acquisition et Interaction en Langue Étrangère: Les Langues des Signes: une perspective sémiogénétique, n. 15, 2001. p 3-

9.http://aile.revues.org/4952001.DELAPORTE, Ives. Les Sourds c'est comme ça: Etnologie de la surdimudité. Paris: Éditions de la Maison des Sciences de l'Homme. 2002.

DERRIDA, Jacques. Y a-t-il une langue philosophique?. Autrement Revue, Paris :n. 102 p.3037, nov. 1988.

DESCARTES, René. Discurso do método. Lisboa: Edições 70. 1987.

DIÁRIO DA REPÚBLICA, 1. ${ }^{a}$ série - N. ${ }^{\circ} 91$ - 12 de Maio de 2008. Lei n. ${ }^{\circ}$ 21/2008 de 12 de Maio de 2008.

DIÁRIO DA REPÚBLICA , Série I-A, N. ${ }^{\circ}$ 218. 20 de Setembro de 1997. Lei Constitucional $\mathrm{n}^{\circ} 1 / 97$, de 20 de setembro de 1997. Quarta revisão constitucional.

FERREIRA, António V. (coord). Gestuário: Língua Gestual Portuguesa. $2^{\mathrm{a}}$ ed. Lisboa: Secretariado Nacional de Reabilitação, 1995.

FERRIOL, Alejandro Sarbach. Que se passa en la clase de filosofia?: Hacia una didáctica narrativa y de investigación. 2006. 646f. Tese (doutoramento em Pedagogia) - Faculdade de Pedagogia, Universidade de Barcelona, Barcelona.

FUSELLIER-SOUZA, Ivani. Processus de création et de stabilisation lexicale en langue des signes (LS) a partir d'une approche semiogénétique. GLOTTOPOL, n. 7, p. 72-95, jan, 2002. 
GARCIA, Brigitte. Sourds, surdité, langue(s) des signes et epistémologie des sciences $d u$ langage : Problématiques de la scripurisation et modélisation de bas niveaux en langue des signes française $(L S F)$. 2010. 302f. Volume I: mémoire de synthèse (Diploma de Habilitation à Diriger des Recherches) -. Université de Paris 8, Paris.

GEX, Maurice. Logique formelle. $3^{\mathrm{a}}$ ed., Neuchâtel: Éditions du Griffon, 1968.

HESSEN, Johannes. Teoria do conhecimento, $6^{\text {a }}$ ed. Coimbra: Arménio Amado Editor Sucessor, 1973.

JEGGLI, M. Francis. L'interprétation français/LSF à l'Université. Langue Française,n. 137, p. 114-123, 2003.

LALANDE, André. Vocabulário-técnico e crítico da Filosofia. Porto: Rés. s/data.

MINEIRO, A.; PEREIRA, J.; DUARTE, L.; MORAIS, I. 2009. Adding pieces to the portuguese sign language lexicon puzzle: three pilot studies. Cadernos de Saúde, Universidade Católica Portuguesa, vol. 2, número especial de Línguas Gestuais, pp. 83-98, 2009.

MORGAN, Gary (eds.). Research methods in sign language studies: A practical guide. UK: John Wiley \& Sons, Inc, 2015.

PERNISS, Pamela. 2015. Collecting and analizing sign language data: Video requirements and use of annotation software. In: ORFANIDOU, Eleni; WOLL, Bencie;

PLATÃO. Teeteto. Lisboa: Fundação Calouste Gulbenkian, 2005.

QUADROS, R. M.; KARNOPP, Lodenir Becker. Língua de sinais brasileira: estudos linguísticos. Porto Alegre: Artmed, 2004.

RUDISILL, John. The transition from studying philosophy to doing philosophy. Teaching Philosophy, v. 34, n. 3, p. 241-271, set. 2011,

SACKS, Oliver. Vendo vozes: Uma viagem ao mundo dos surdos. São Paulo: Companhia das Letras, 2002.

SALLANDRE, Marie Anne. Les unités du discours en langue des signes française: tentative de catégorisation dans le cadre d'une grammaire de l'iconicité. 2003. 307f. Tese (Doctorat en Sciences du Langage) - Université de Paris 8, Paris.

SALLANDRE M. A.; CUXAC, C. Iconicity in sign language: a theoretical and methodological point of view. In: WACHSMUTH, I.; SOWA, T. (eds.). Gesture and Sign Language in Human-Computer Interaction. Springer, 2002.

SHAUMYAN, Sebastian. Signs, mind and reality: A theory of language as the folk model of the world. Amsterdam/Philadelphia: John Benjamins Publishing Company, 2006. 
CORREIA, F. S.; COELHO, O.

TAUB, Sarah F. Language from the body: Iconicity and metaphor in american sign language. Cambridge: Cambridge University Press, 2004.

VERMEERBERGER, Myriam. Past and current trends in sign language research. Language and Communication, vol. 26, n. 2, p.) 168-192, abr. 2006.

WILCOX, Phyllis P. Metaphor in american sign language. Washington DC: Gallaudet University Press, 2000.

Data de recebimento: $21 / 08 / 2015$

Data de aceite: $27 / 10 / 2015$ 